\title{
Research priorities in occupational health in Italy
}

\author{
S Iavicoli, A Marinaccio, N Vonesch, C L Ursini, C Grandi, S Palmi
}

\begin{abstract}
Objective-To find a broad consensus on research priorities and strategies in the field of occupational health and safety in Italy.

Methods-A two phase questionnaire survey was based on the Delphi technique previously described in other reports. 310 Occupational safety and health specialists (from universities and local health units) were given an open questionnaire (to identify three priority research areas). The data obtained from respondents (175, $56.4 \%$ ) were then used to draw up a list of 27 priority topics grouped together into five macrosectors. Each of these was given a score ranging from 1 (of little importance) to 5 ( extremely important). With the mean scores obtained from a total of 203 respondents $(65.4 \%)$, it was possible to place the 27 topics in rank order according to a scale of priorities.

Results-Among the macrosectors, first place was given to the question of methodological approach to research in this field, and for individual topics, occupational carcinogenesis and quality in occupational medicine were ranked first and second, respectively. The question of exposure to low doses of environmental pollutants and multiple exposures ranked third among the priorities; the development of adequate and effective approaches and methods for worker education and participation in prevention was also perceived as being an important issue (fourth place).
\end{abstract}

Conclusions-This study (the first of its kind in Italy) enabled us to achieve an adequate degree of consensus on research priorities related to the protection of occupational health and safety. Disparities in the mean scores of some of the issues identified overall as being research priorities, seem to be linked both to geographical area and to whether respondents worked in local health units or universities. This finding requires debate and further analysis.

(Occup Environ Med 2001;58:325-329)

Keywords: research priorities; occupational health; strategies

There has been a call for a more rational use of the resources available for research development in the occupational health sector. Rapid changes in the workplace and concomitant health risks require an adequate response on the part of the scientific community.
Although many obvious forms of occupational disease have been wiped out, and many of the traditional risks are now under control, thanks partly to the introduction of European regulations such as the EEC Directive 89/391, new problems associated mainly with rapid technological development and continuous innovations in workplace organisation, make adequate prevention an important requirement.

If research is to be directed towards the real need for health and safety in the workplace, all the parties interested in this field must be involved in preventive action.

This need is widely understood in Italy where important scientific firms and organisations specialising in this sector, such as the Italian Associate Consultancy Board for Prevention and the Italian Association for Occupational Health and Industrial Hygiene, have undertaken initiatives to promote prevention.

There are also some international reports that point in this direction: the paper Global strategy for occupational health for all produced by World Health Organisation Collaboration Centres lists among its 10 primary objectives that of increasing and rationalising research in the occupational safety and health (OSH) sector. ${ }^{1}$ An EC analysis has also confirmed this need. ${ }^{2}$

In Italy, the occupational health sector has developed enormously in recent years, partly as a result of EC Directives. In all workplaces where employees are present, occupational risks must be evaluated and workers who are exposed to specific risks - for example, lead, asbestos, noise, carcinogenic agents, manual loading, biological agents, visual display terminals, etc-must be monitored by an occupational health specialist. The growing complexity of demand and the rapidly expanding work market have highlighted the need for applied research in the OSH sector, particularly in small and medium sized industries where the greatest number of workers are employed, and where it is more dificult to introduce occupational health programmes. In Italy, research in the occupational health sector is carried out by University Institutes of Occupational Medicine and Hygiene, the National Institute for Occupational Safety and Prevention (ISPESL) and some local health units. Some hospitals and treatment research institutes together with a few mainly state run organisations, complete the picture.

Research financing in the occupational health sector comes from public funds mainly through the National Health Fund which is administered chiefly by the Ministry of Health, and, to a lesser extent, by the Ministry of Labour and the Ministry for Higher Education 
Table 1 Differences in scores between local health units and universities (1-27 topics)

\begin{tabular}{|c|c|c|c|c|c|c|}
\hline $\begin{array}{l}\text { Macro } \\
\text { sector }\end{array}$ & Topic identified & Rank & $\begin{array}{l}\text { Mean } \\
\text { score }\end{array}$ & $\begin{array}{l}\text { Mean score in } \\
\text { local health units }\end{array}$ & $\begin{array}{l}\text { Mean score in } \\
\text { university }\end{array}$ & $\begin{array}{l}\text { Significance of differences between } \\
\text { mean score in local health units and } \\
\text { university }{ }^{*} 95 \% \text { CI and } \star * 99 \% \text { CI) }\end{array}$ \\
\hline $\mathrm{D}$ & Occupational carcinogenesis & 1 & 4.32 & 4.33 & 4.31 & \\
\hline $\mathrm{E}$ & Quality in occupational medicine & 2 & 4.15 & 4.41 & 3.88 & $\star \star($ Local health units> university) \\
\hline $\mathrm{D}$ & Exposure to low doses and multiple exposure & 3 & 4 & 4 & 3.99 & \\
\hline $\mathrm{E}$ & Worker information, education, and participation & 4 & 3.89 & 4.04 & 3.73 & $\star$ (Local health units> university) \\
\hline $\mathrm{E}$ & $\begin{array}{l}\text { Organisation, strategies, and optimisation of prevention and safety } \\
\text { services at the workplace }\end{array}$ & 5 & 3.87 & 4.38 & 3.34 & $\star \star($ Local health units> university) \\
\hline $\mathrm{E}$ & Biological monitoring: identification of markers for low dose exposure & 6 & 3.83 & 3.72 & 3.94 & \\
\hline A & New work related diseases & 7 & 3.77 & 3.75 & 3.79 & \\
\hline $\mathrm{E}$ & Medical surveillance and work ability criteria & 7 & 3.77 & 3.87 & 3.67 & \\
\hline A & Work accidents & 9 & 3.75 & 3.99 & 3.5 & $\star \star($ Local health units $>$ university $)$ \\
\hline B & Electromagnetic fields & 10 & 3.69 & 3.68 & 3.71 & \\
\hline $\mathrm{E}$ & Work organisation and new types of work & 11 & 3.66 & 3.73 & 3.59 & \\
\hline A & Musculoskeletal and repetitive trauma disorders & 12 & 3.64 & 3.78 & 3.5 & ${ }^{\star}($ Local health units $>$ university $)$ \\
\hline $\mathrm{C}$ & Healthcare and hospital sector & 13 & 3.61 & 3.52 & 3.7 & \\
\hline B & Asbestos substitute fibres & 14 & 3.55 & 3.51 & 3.6 & \\
\hline $\mathrm{D}$ & Individual susceptibility and development of susceptibility indicators & 15 & 3.53 & 3.23 & 3.84 & $\star \star($ Local health units $<$ university) \\
\hline A & Occupational allergies & 16 & 3.46 & 3.42 & 3.5 & \\
\hline B & Biological agents & 17 & 3.44 & 3.46 & 3.41 & \\
\hline A & Occupational asthma and respiratory diseases & 18 & 3.43 & 3.28 & 3.57 & $\star$ (Local health units $<$ university) \\
\hline $\mathrm{C}$ & Agriculture & 19 & 3.38 & 3.45 & 3.3 & \\
\hline B & Load handling & 20 & 3.36 & 3.53 & 3.19 & $\star$ (Local health units > university) \\
\hline $\mathrm{C}$ & Special populations at risk (elderly, minor, and disabled people) & 21 & 3.33 & 3.42 & 3.24 & \\
\hline B & Occupational exposure to urban chemical pollutants & 22 & 3.32 & 3.12 & 3.53 & *(Local health units $<$ university) \\
\hline $\mathrm{D}$ & Mechanisms of action of occupational stress and occurrence of diseases & 22 & 3.32 & 3.3 & 3.33 & \\
\hline A & Reproductive and pregnancy disorders & 24 & 3.31 & 3.39 & 3.22 & \\
\hline $\mathrm{E}$ & Methods of assessing and measuring occupational stress & 25 & 3.29 & 3.28 & 3.29 & \\
\hline $\mathrm{C}$ & Air quality and indoor environments & 26 & 3.14 & 2.94 & 3.34 & $\star$ (Local health units $<$ university) \\
\hline $\mathrm{D}$ & Mechanisms of skin absorption of xenobiotics & 27 & 2.93 & 2.81 & 3.04 & \\
\hline
\end{tabular}

and Scientific and Technological Research. The Italian regions also provide finance, and international funds are made available through the European Commission.

The overall figure for funding in the Occupational Health sector is, however, low compared with other branches of medical research.

Despite a recent study showing that the extremely high direct and indirect costs of work accidents and occupational diseases were equal to those sustained for cancer and cardiovascular diseases, resources earmarked for research in the occupational health sector are much lower than those allocated to other disciplines. ${ }^{3}$

In the past, in other countries, studies have been successfully undertaken to identify research priorities in the occupational health sector. $^{24-11}$

These include the Delphi studies carried out in the United Kingdom by Harrington and Calvert. In consecutive surveys that targeted firstly British occupational health physicians, and secondly United Kingdom personnel managers, ${ }^{45}$ they identified research priorities in the field of occupational health. In the United States the National Institute for Occupational Safety and Health has been promoting since 1995 a programme called "national occupational research agenda" (NORA). This initiative, which has involved a large part of the scientific community, social parties, and government representatives, has led to the identification of 21 priority research issues in the $\mathrm{OSH}$ sector. $^{8}$

A research group has been set up at ISPESL to identify research priorities that would meet the specific requirements of the Italian $\mathrm{OSH}$ sector.

The aim of the present study was to identify by means of a model previously tested in the United Kingdom, and with the aid of a wide range of leading research experts in the occupational health field, research priorities in this sector.

To this end, a list was made of all the university professors, lecturers, and researchers engaged in this field, as well as the directors of prevention departments in local health units that are part of the National Health Service.

Academics are in fact one of the main institutional sources of research in Italy, whereas local health unit prevention departments that carry out, on behalf of the National Health Service, OSH functions all over the country, are sometimes leading centres for research in this sector.

\section{Methods}

The Delphi method was used to find a broad consensus on occupational health research priorities in Italy. The technique adopted by Harrington and Calvert was modified to suit the particular characteristics existing in the occupational health sector in this country. ${ }^{45}$ In fact we considered it necessary to canvass both academics engaged mainly in research and experts involved in practical prevention in sectors such as NHS departments of prevention and to study the differences in geographical location of the experts in the light of significant differences in productive structure and levels of employment throughout the country.

Two groups composed of all the academics in the field of occupational health and all the local health prevention services were targeted.

In this context, 131 university professors, lecturers, and researchers from Italian occupational health departments or institutes took part in the study together with 179 directors from NHS local health unit prevention departments, evenly distributed all over the country.

The 310 chosen subjects received a first questionnaire (accompanied by a letter explaining the aims of the study) in which they 
Table 2 Differences in scores between geographical areas (1-27 topics)

\begin{tabular}{|c|c|c|c|c|c|c|c|}
\hline $\begin{array}{l}\text { Macro } \\
\text { sector }\end{array}$ & Topic identified & Rank & $\begin{array}{l}\text { Mean } \\
\text { score }\end{array}$ & $\begin{array}{l}\text { Mean score in } \\
\text { northern Italy }\end{array}$ & $\begin{array}{l}\text { Mean score in } \\
\text { central Italy }\end{array}$ & $\begin{array}{l}\text { Mean score in } \\
\text { southern Italy }\end{array}$ & $\begin{array}{l}\text { Significance of differences between } \\
\text { mean score in north, centre, and } \\
\text { south }\left({ }^{\star} 95 \% \text { CI and }{ }^{\star} 99 \% \text { CI) }\right.\end{array}$ \\
\hline $\mathrm{D}$ & Occupational carcinogenesis & 1 & 4.32 & 4.33 & 4.3 & 4.38 & \\
\hline $\mathrm{E}$ & Quality in occupational medicine & 2 & 4.15 & 4.07 & 4.19 & 4.21 & \\
\hline $\mathrm{D}$ & Exposure to low doses and multiple exposure & 3 & 4 & 3.97 & 4.06 & 3.94 & \\
\hline $\mathrm{E}$ & Worker information, education, and participation & 4 & 3.89 & 3.66 & 3.94 & 4.17 & $\star($ South $>$ north $)$ \\
\hline $\mathrm{E}$ & $\begin{array}{l}\text { Organisation, strategies, and optimisation of prevention } \\
\text { and safety services at the workplace }\end{array}$ & 5 & 3.87 & 3.84 & 3.82 & 4 & \\
\hline $\mathrm{E}$ & $\begin{array}{l}\text { Biological monitoring: identification of markers for low } \\
\text { dose exposure }\end{array}$ & 6 & 3.83 & 3.84 & 3.81 & 3.85 & \\
\hline A & New work related diseases & 7 & 3.77 & 3.77 & 3.69 & 3.94 & \\
\hline $\mathrm{E}$ & Medical surveillance and work ability criteria & 7 & 3.77 & 3.71 & 3.79 & 3.85 & \\
\hline A & Work accidents & 9 & 3.75 & 3.53 & 3.89 & 3.88 & \\
\hline B & Electromagnetic fields & 10 & 3.69 & 3.67 & 3.53 & 4.02 & $\star($ South $>$ centre $)$ \\
\hline $\mathrm{E}$ & Work organisation and new types of work & 11 & 3.66 & 3.53 & 3.8 & 3.6 & \\
\hline A & Musculoskeletal and repetitive trauma disorders & 12 & 3.64 & 3.75 & 3.67 & 3.42 & \\
\hline $\mathrm{C}$ & Healthcare and hospital sector & 13 & 3.61 & 3.51 & 3.61 & 3.79 & \\
\hline B & Asbestos substitute fibres & 14 & 3.55 & 3.51 & 3.65 & 3.5 & \\
\hline $\mathrm{D}$ & $\begin{array}{l}\text { Individual susceptibility and development of susceptibility } \\
\text { indicators }\end{array}$ & 15 & 3.53 & 3.61 & 3.55 & 3.36 & \\
\hline A & Occupational allergies & 16 & 3.46 & 3.58 & 3.51 & 3.23 & \\
\hline B & Biological agents & 17 & 3.44 & 3.44 & 3.36 & 3.56 & \\
\hline A & Occupational asthma and respiratory diseases & 18 & 3.43 & 3.4 & 3.44 & 3.48 & \\
\hline $\mathrm{C}$ & Agriculture & 19 & 3.38 & 3.15 & 3.29 & 3.88 & $\begin{array}{l}\star \star(\text { South }>\text { north }) \\
\star \star(\text { South }>\text { centre })\end{array}$ \\
\hline B & Load handling & 20 & 3.36 & 3.38 & 3.42 & 3.23 & \\
\hline $\mathrm{C}$ & $\begin{array}{l}\text { Special populations at risk (elderly, minor, and disabled } \\
\text { people) }\end{array}$ & 21 & 3.33 & 3.26 & 3.54 & 3.1 & $\star($ Centre $>$ south $)$ \\
\hline $\mathrm{B}$ & Occupational exposure to urban chemical pollutants & 22 & 3.32 & 3.19 & 3.35 & 3.48 & \\
\hline $\mathrm{D}$ & $\begin{array}{l}\text { Mechanisms of action of occupational stress and } \\
\text { occurrence of diseases }\end{array}$ & 22 & 3.32 & 3.4 & 3.3 & 3.26 & \\
\hline A & Reproductive and pregnancy disorders & 24 & 3.31 & 3.3 & 3.42 & 3.1 & \\
\hline $\mathrm{E}$ & Methods of assessing and measuring occupational stress & 25 & 3.29 & 3.34 & 3.26 & 3.28 & \\
\hline $\mathrm{C}$ & Air quality and indoor environments & 26 & 3.14 & 2.96 & 3.14 & 3.44 & $\star($ South $>$ north $)$ \\
\hline $\mathrm{D}$ & Mechanisms of skin absorption of xenobiotics & 27 & 2.93 & 2.92 & 2.99 & 2.85 & \\
\hline
\end{tabular}

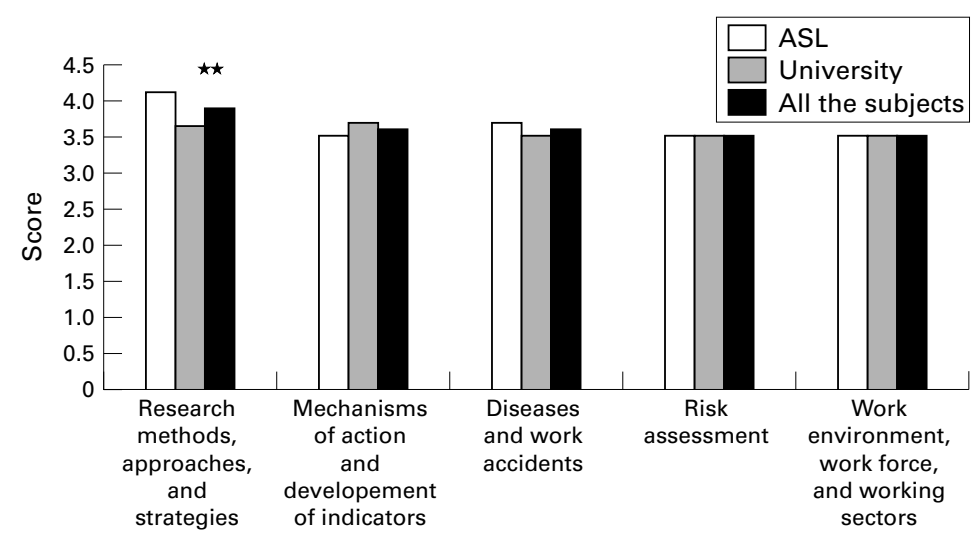

Figure 1 Macrosectors by mean scores ordered by rank in all the subjects, local health units, and university. ${ }^{\star} p<0.01$.

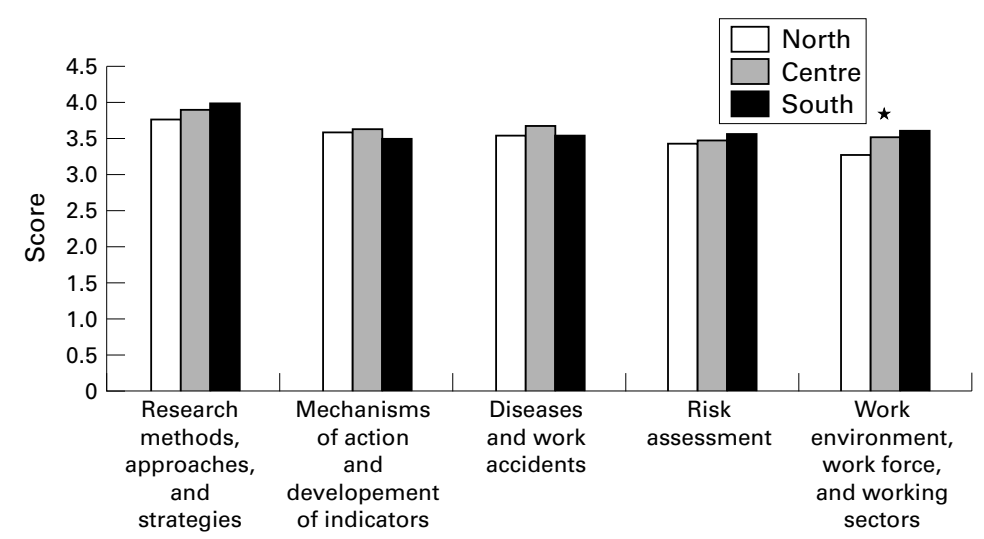

Figure 2 Macrosectors by mean scores ordered by rank in northern, central, southern Italy. ${ }^{\star} p<0.05$. were asked to state briefly, in random order, the three occupational health issues that, in their opinion, should be given priority in research activity.

By analysing the topics indicated by respondents it was possible to draw up a list of 27 priority areas grouped together into five macrosectors.

These macrosectors were classified as follows: $(A)$ diseases and work accidents; $(B)$ risk assessment; $(C)$ work environment, workforce, and working sectors; $(D)$ mechanisms of action and development of indicators; and $(E)$ research methods, approaches, and strategies (tables 1 and 2 and figs 1 and 2).

The experts taking part in the study were then canvassed with a second questionnaire. This time they were asked to give each of these topics a score based on the following priority scale: 1 of little importance; 2 moderately important; 3 of average importance; 4 very important; 5 extremely important.

In both phases the subjects canvassed were approached by sending them reminders through the post.

Responses to the second questionnaire were analysed to calculate the mean score for each area and its ranking relative to the whole group of experts and to the two groups of academics and local health unit experts, taken separately. The degree of consensus in these rankings was then determined together with the significance of the disparities in the mean scores of each variable in the two groups. Non-parametric tests (Mann-Whitney $U$ test and KolmogorovSmirnov $Z$ test) were performed to assess difference in distribution for each variable in the two groups. Questionnaire data were also 
analysed relative to the geographical location of the respondents (careful attention was given to the significance of differences in mean scores allocated by experts from northern, central, and southern Italy). Different geographical areas have a different productive structure and different employment levels. The north is the most industrialised area, whereas in the predominantly agricultural economy of the south there is a high level of unemployment, and the economy of central Italy is linked principally to the "service" sector.

\section{Results}

During the first phase, 310 questionnaires were sent out to canvass 179 managers of local health unit prevention services and 131 university experts. Of the 175 responses received, 75 were from the local health units and 100 from academics representing a total of $56.4 \%$ of respondents $(41.9 \%$ from local health units and $76.3 \%$ from universities).

Of the 203 experts who replied in the second phase, 102 were from local health units and 101 from universities, representing a total of $65.5 \%$ respondents $(57 \%$ from local health units and $77.1 \%$ from universities). All the 175 respondents to the first questionnaire answered the second one as well.

An analysis of results indicated that there was moderate agreement on the ranking of variables in the two groups (table 1). Spearman's cograduation index (which measures the extent of correlation between rankings in the two groups) was found to be 0.54 , thereby suggesting that the hypothesis of absence of cograduation could be rejected with $99 \%$ probability. Significant differences resulting in a few cases from an analysis of the disparities in the mean scores of each variable are confirmed by the results of non-parametric tests (MannWhitney $U$ test and the Kolmogorov-Smirov $Z$ test). Analysis by geographical area also indicated some significant differences in the mean scores of variables (especially in north/ south and centre/south comparisons, table 2). Although experts were not asked to attribute a score to the macrosectors, these were nevertheless assessed by giving them a score equal to the median of values attributed by the experts to individual corresponding variables. The macrosectors then underwent the same data processing as was used for the individual variables.

Limited differences were found in the rank order attributed to the five macrosectors among local health units and academics; the sector entitled "research methods, approaches, and strategies" stands out from the rest (fig 1 and 2).

\section{Discussion}

A satisfactory number of subjects from the two selected groups participated in the study. In fact more than three quarters of the academics replied to both questionnaires. When considering the quota of respondents from the local health units $(41.9 \%$ in the first phase and $57 \%$ in the second), it should be noted that, at the time of the survey, although a law had been passed to set up departments of prevention in local health units, checks on whether questionnaires or reminders had been received showed that, in some cases, the department was not yet operational or the director had not been appointed.

Analysis showed that there was consensus among the group of specialists on the research priorities indicated. Results obtained by the Delphi technique can typically be interpreted in different ways.

There was little difference between the research issues indicated by academics and those chosen by the Directors of local health unit prevention departments. For 17 out of the 27 topics there is little statistical difference in the mean priority ranking. In the remaining 10 priority areas, differences can provide useful material for discussion.

Local health unit prevention department directors attributed higher priority to more practical topics that could be more closely linked to research findings. This is hardly surprising as these specialists are engaged all over the country in finding practical solutions to occupational issues. Local health unit specialists attribute higher priority to quality in occupational medicine $(\mathrm{p}<0.01)$, organisation, strategies, and optimisation of health at the workplace, to worker information, education, and participation $(\mathrm{p}<0.05)$, musculoskeletal repetitive trauma disorders $(\mathrm{p}<0.05)$, and special population at risk $(\mathrm{p}<0.05)$.

Analysis of the priority ranking attributed to research issues on the basis of the geographical location of respondents showed only limited differences (significant differences were found for only six of the topics). Nevertheless this analysis is very important in the Italian situation because of the marked difference in economic development between the north and south of the country. There is a significant difference in the high priority given to agriculture $(\mathrm{p}<0.01)$ in the south compared with the north and the centre. This finding may be related to the many farm workers employed in the south on very small, mainly family run farming units, where it is particularly difficult to apply adequate measures of prevention.

In the overall ranking of research priorities, all the experts attributed first place to occupational carcinogenesis. This result was confirmed by the presence of other topics that can, in one way or another, be linked to the same subject (exposure to low doses and multiple exposures, biological monitoring, identification of markers for low dose exposures, electromagnetic fields, asbestos substitute fibres, occupational exposures to urban chemical pollutants), thus providing a more complete and concise overall view. It is not surprising that this subject is considered to be so important. Even the most conservative estimates indicate that occupational tumours account for 6000-7000 deaths a year in Italy, and in view of the growing number of workers exposed to carcinogenic substances, many authors firmly think this figure to be underestimated. ${ }^{13}{ }^{14}$ In fact, CAREX, the international information index of exposures to known and 
possible carcinogens, has calculated that 4200000 Italian workers (24\% of the total working population) are exposed to carcinogenic substances. ${ }^{14}$

In Italy, research in this sector is of vital importance to obtain useful information on prevention to meet the requirements of a rapid evolution of knowledge in the biomolecular field and to develop the epidemiological surveillance of work related tumours. Furthermore, in recent years there has been a marked increase in legal disputes between exposed workers (or formerly exposed workers) and employers over prevention of exposure to carcinogenic substances and insurance claims. These elements help to explain the importance Italian experts give to this subject compared with other research priority studies mentioned previously. ${ }^{4}{ }^{10}$

The other priority issue that emerged from the present study was quality in occupational medicine. The very few studies on this topic that are published in Italy highlights the gap between the demand that emerged in this survey and the $\mathrm{OSH}$ research projects currently undertaken.

The Italian Association of Occupational Health and Industrial Hygiene recently set up a working party to study and develop quality in occupational medicine.

Although no significant differences were found in the rank order attributed to the five macrosectors, the sector entitled "research methods, approaches, and strategies" stands out from the rest. This finding is interesting as it reflects the way recent $\mathrm{OSH}$ research has developed compared with the past when more emphasis was given to diseases, risk factors, or productive sectors. Some international studies, such as the survey to identify research priorities in the United States, have also attributed great importance to this sector. Of the 21 topics in the NORA, as many as eight come under the major heading research tools and approaches.

Without losing sight of methodological differences and the specific situation in each country, it is worth making a comparison with similar initiatives such as the NORA programme and Delphi studies undertaken in other countries, as they have led to the identification of many common research areas. More than half of the topics in the 21 research priorities are the same as those identified in our study. ${ }^{8}$

This induces us to reflect that since occupational health problems are common to all workplaces, a better understanding and evaluation of these issues would make it possible to tackle them in a more organised way, thereby optimising the use of available resources.

In view of the highly qualified specialists who took part in this survey and the degree of consensus reached, we can conclude that the present study (the first of its kind in Italy) offers a valid contribution to research planning in the Italian $\mathrm{OSH}$ sector.

1 World Health Organization. Global strategy on occupational health for all. Geneva, WHO, 1995. (WHO/OCH/95.1.)

2 European Commission. Work and health scientific basis of progress in the working environment. Report EUR 15980 EN $D G$ Employment, Industrial Realtions and Social Affairs. Luxembourg: EC, 1995.

3 Leigh J, Macaskill P, Kuosma E, et al. Global burden of disease and injury due to occupational factors. Epidemiology 1999;10:626-31.

4 Harrington JM. Research priorities in occupational medicine: a survey of United Kingdom medical opinion by the Delphi technique. Occup Environ Med 1994;51:289-94.

5 Harrington JM, Calvert IA. Research priorities in occupational medicine: a survey of United Kingdom personnel tional medicine: a survey of United Kingdon

6 Brink AJ. Medical research in the Republic of South Africa. $S$ Afr Med F 1997;51:493-4.

7 Rogers B. Establishing research priorities in occupational health nursing. American Association of Occupational Health Nurses fournal 1989;37:493-500.

8 Rosenstock L, Olenec C, Wagner GR. The national occupational research agenda: a model of broad stakeholder input into priority setting. Am F Public Health 1998;88:353-6.

9 Yerxa EJ. Research priorities. Am f Occup Ther 1983;37:699.

10 Van Der Beek AJ, Fring Dresen MH, Van Diijk FJ. Priorities in occupational health research: a Delphi study in the in occupational health research: a Delphi study

11 MacDonald EB, Ritchie KA, Murray KJ, et al. Requirements for occupational medicine training in Europe: a Delphi study. Occup Environ Med 2000;57:98-105.

12 Doll R, Peto R. The causes of cancer: quantitative estimates of avoidable risks of cancer in the United States today. $\mathcal{F}$ Natl Cancer Inst 1981;66:1192-308.

3 Cocco P. Tumori e lavoro: a 20 anni da "the causes of cancer" di Doll e Peto. Med Lav 2000;91:14-23.

14 Mirabelli D. Estimate of the number of workers exposed to cancer causing agents in Italy within the framework of the European study CAREX . Epidemiol Prev 1999;23:346-59.

\section{Rejected manuscripts}

Authors whose submitted articles are rejected will be advised of the decision and one copy of the article, together with any reviewer's comments, will be returned to them. The
Fournal will destroy remaining copies of the article but correspondence and reviewers' comments will be kept. 